\title{
Wrinkle scaly carcinoma anal in relation to a case.
}

\section{Rovira Argelagués Montserrat*, Puigdollers Pérez}

Department of Proctology and General Surgery, Hospital De Mollet Del Vallès, Spain

Accepted on March 13, 2019

\section{Clinical Image}

Anal wrinkle scaly carcinomas are a rare variant of scaly carcinoma, frequent in young women in the vulvar zone and associated with human papilloma virus infection. We present the case of a 72-year-old man with a history of hypertension, involving right hemicolectomy 15 years ago by adenocarcinoma of the colon and was free of disease. Go to the prothologic consultation for exofitic lesion in the anal margin of 2 months of evolution with occasional proctororrhagia. On exploration, a tumor of $2 \mathrm{~cm}$ diameter, which easily blurs with friction, and does not adhere to deep plans (Figures 1 and 2). Straight touch and rigid rectoscope were normal. Complete exhaustion of the lesion with extensive safety margins. The pathological anatomy reported wrinkle scaly carcinoma with free resection margins. Due to the histological diagnosis a smear and anal-channel cytology were performed for HPV serotyping and evaluation, which reported HPV 6 with normal cytology. Currently 2 years of surgery and the patient is asymptomatic [1-3].

\section{References}

1. http://www.conganat.org/7congreso/final/vitaImpresion.asp.

2. Zanini M, Wulkan C, Paschoal FM, et al. Anbras dermatol. Rio de Janeiro. 2004;79(5):619-21.

3. Alemany L, Saunier M, Alvarado I, et al. HPV DNA prevalence and type distribution in anal carcinomas world wie. Int J Cancer. 2015;136(1):98-107.

\section{*Correspondence to:}

Rovira Argelagués Montserrat, Ph.D., Department of Proctology and General Surgery, Hospital De Mollet Del Vallès, Spain

Tel: +0034-659-92-31-93

E-mail: rat_rovira@hotmail.com

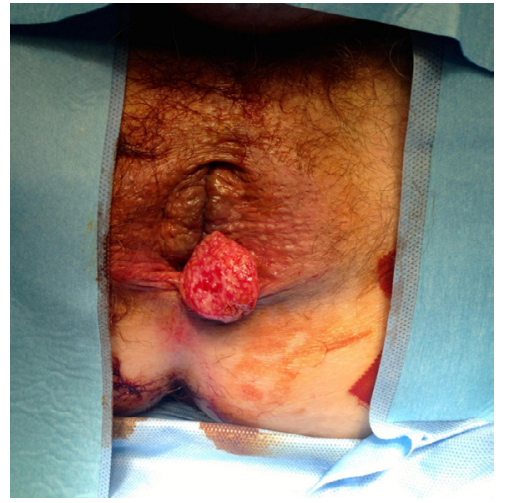

Figure 1. Image $n^{\circ} 1$.

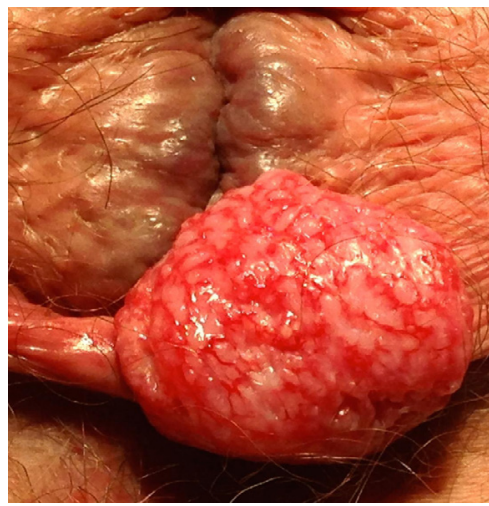

Figure 2. Image $n^{\circ} 2$. 